\title{
How do the Key Determinants of a Distributed Planning Process Impact on the Performance of a Supply Chain?
}

\author{
Julien François ${ }^{1}$, Uche Okongwu ${ }^{2}$, Jean-Christophe Deschamps ${ }^{1}$, \\ and Matthieu Lauras ${ }^{3}$ \\ ${ }^{1}$ University of Bordeaux, IMS \\ 351 cours de la Libération, 33405 Talence (France) \\ julien.francois@ims-bordeaux.fr, \\ jean-christophe.deschamps@ims-bordeaux.fr \\ ${ }^{2}$ Toulouse Business School \\ Department of Industrial Organisation, Logistics and Technology \\ 20 Boulevard Lascrosses \\ BP 7010, 31068 Toulouse Cedex 7 (France) \\ ${ }^{3}$ Université de Toulouse, Mines Albi \\ Department of Industrial Engineering \\ Route de Teillet, 81013 Albi Cedex 9 (France)
}

\begin{abstract}
As firms search to maximise value through the effective management of their various business activities, it is increasingly important to identify and understand the key factors that can significantly impact on the performance of the supply chain. The Supply Chain Operations Reference (SCOR) model enables to identify four distinct processes (plan, source, make and deliver) that constitute a supply chain. If many researchers have studied the last three processes (source, make and deliver), the relationship between the determinants of the planning process and supply chain performance has not been sufficiently explored. This paper therefore aims to identify and analyse the determinants of a distributed planning process that impact on the performance of a supply chain, including both financial and non-financial elements. It proposes a conceptual framework and a simulation model that can be used to improve the performance of a supply chain in terms of efficiency, flexibility, effectiveness and responsiveness.
\end{abstract}

Keywords: Planning process; supply chain management; performance measurement; flexibility; efficiency; effectiveness; responsiveness.

\section{Introduction}

Supply chains (SC) are facing growing pressures due to globalisation, harsh competition, fluctuating energy prices and volatile financial markets. Their strategic goals are set to reduce costs, improve customer services, increase reliability and efficiency of operations, and fast delivery of products to markets. These strategic goals can be achieved by effectively designing, monitoring and controlling the various processes that constitute the SC. The Supply Chain Operations Reference (SCOR) model enables to identify four main processes (plan, source, make and deliver) that constitute a 
supply chain. The determining factors of each of these processes can impact on the performance of the supply chain.

If many researchers have studied the relationship between the various determinants of the last three processes (source, make and deliver) and supply chain performance, the determinants of the planning process have not been sufficiently explored. Moreover, the few studies that have been done on this topic are generally limited not only to manufacturing (Wacker and Sheu, 2006; Olhager and Selldin, 2007) but also to the financial aspect of performance (Reiner and Hofmann, 2006). This paper aims to study how the determining factors of the planning process impact on both the financial and non-financial elements of supply chain performance.

We will start by developing our research framework before presenting the simulation model. Then, the results of the simulation will be discussed with respect to the determining factors and performance criteria identified in the framework.

\section{Research Framework}

For the purpose of our study, it can simply be said that "a supply chain links production units, one unit's outputs providing inputs into another unit or multiple units" (De Man and Burns, 2006). It follows that supply chain management (SCM) has to do with the planning, execution and coordination of the production units.

A thorough literature review (Chase et al., 2004; Stevenson, 2005; Slack et al., 2007) enabled us to identify 10 determining factors of the planning process (see Table 1). These are: forecast accuracy and stability, planning horizon, time bucket, frozen time fence, manufacturing capacity, lot sizing, inventory management, cycle time, sequencing and scheduling.

Table 1. Determining factors of the planning process

1. Planning horizon

- Small (e.g. monthly)

- Medium (e.g. quarterly)

- Large (e.g. yearly)

4. Manufacturing capacity

- Constant output rate

- Chase demand

- Mixed strategy

7. Sequencing

- Earliest Due Date

- First In, First Out

- Last In, Last Out

- Longest Processing Time

- Shortest Processing Time
2. Time bucket

- Small (e.g. daily)

- Medium (e.g. weekly)

- Large (e.g. monthly)

5. Lot sizing

- Lot-for-lot

- Fixed Lot size

- Fixed-period quantity

8. Scheduling

- Forward

- Backward

9. Cycle time

- Slow

- Fast
3. Frozen time fence

- Small (e.g. 1 week)

- Medium (e.g. 1 month)

- Large (e.g. 1 quarter)

6 . Inventory management - Low safety stock

- Medium safety stock

- High safety stock

10. Forecast accuracy and stability

- Low confidence

- medium confidence

- high confidence

These determining factors can positively or negatively impact on the performance of the supply chain (SC). Walters (2006) and Rainbird (2004) argue that while the upstream part of the SC lays emphasis on efficiency (which consists of minimising 
operational cost), the downstream part lays emphasis on effectiveness (which entails an effective response to customer expectations). In other words, the upstream SC tends to be "lean" (efficient) by eliminating wastes while the downstream SC tends to be "agile" (effectively responsive) by providing speedy and accurate response to customer expectations. The expression "effectively responsive" could be broken down into two components: effectiveness (which measures the completeness of the order) and responsiveness (which measures the speed at which the order is delivered). Speed and completeness can be obtained by incorporating flexibility in the design of the supply chain.

It follows that a supply chain can be designed, planned and controlled such as to maximise efficiency, effectiveness or responsiveness. On the other hand, the aim could be to achieve a balance between any two or all of these criteria. A system that aims simultaneously for efficiency and effectiveness/responsiveness/flexibility is termed to be "leagile". Naylor et al. (1999) defined leagility as: "the combination of the lean and agile paradigms within a total supply chain strategy by positioning the customer order decoupling point so as to best suit the need for responding to a volatile demand downstream yet providing level scheduling upstream from the decoupling point." Partial leagility can be achieved by searching for a trade-off between efficiency and effectiveness or between efficiency and responsibility.

For the purpose of this paper, we will adopt the following restrictive and onedimensional (or single factor) definitions:

- Flexibility is the range (number) of options available to do things and this can be defined as the range of options designed into the supply chain, which will enable it to fulfil customer orders.

- Efficiency is doing things right (Zokaei and Hines, 2007) and this can be defined as the cost of fulfilling customer orders.

- Effectiveness is doing the right thing (Zokaei and Hines, 2007) and this can be defined as fulfilling orders exactly as they are requested by customers (that is, the completeness of customer orders).

- Responsiveness is doing things quickly and this can be defined as the speed at which customer orders are fulfilled.

Given that flexibility (as we have defined it) is a rigid capability initially designed into the supply chain, only the last three criteria can be used to measure the performance of the supply chain. If leanness is linked to efficiency, agility is linked to effectiveness and/or responsiveness, and leagility is linked to all three. This leads to seven possible supply chain strategies

1) Efficiency

2) Effectiveness

3) Responsiveness

4) Agility (effectiveness, responsiveness and flexibility)

5) Partial effective leagility (efficiency, effectiveness and flexibility)

6) Partial responsive leagility (efficiency, responsiveness and flexibility)

7) Leagility (efficiency, effectiveness, responsiveness and flexibility) 
In a nutshell, we can say that these performance criteria and strategies are based on the following supply chain objective: the supply chain should aim to deliver the right quantity ordered by the customer, at the right time and at minimum cost. In this paper, we simply use efficiency to measure the cost component of the above definition, effectiveness to measure the "right quantity" component and responsiveness to measure the "right time" component.

This framework is represented graphically in Figure 1. It can be used by the planning manager to determine the set of factors that would enable to achieve specific performance objectives, depending on the desired supply chain strategy.

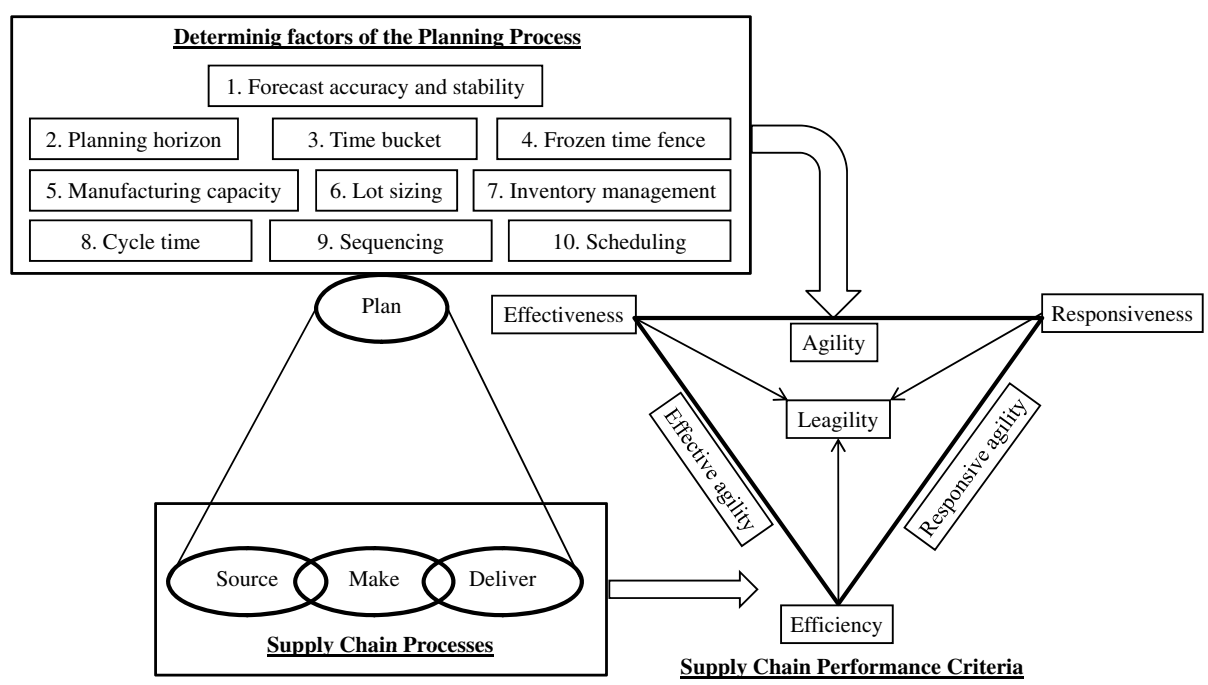

Fig. 1. Linking the determining factors of the planning process to supply chain performance

\section{Planning Process Modelling}

The distributed planning process simulation is based on a generic linear programming model developed by Francois et al. (2005). The model plans production, inventory levels, replenishment and delivery according to customer demand. In a summarized form, we show hereafter the notations and mathematical model used to describe decision making with respect to the planning process of each of the SC industrial partners. Equations number 2 characterize stock levels while expressions number 3 model product backorders (late deliveries) and shortages (considered as never delivered at the end of the delivery lead time acceptable to the customer). Constraints number 4 represent capacity restrictions with an additional capacity for production while constraints number 5 correspond to the two lot-sizing strategies studied in this paper. A "lot-for-lot" strategy (rule 1) is active for $\mathrm{B}=0$ and a "fixed-periodquantity" strategy (rule 2) is applied for $\mathrm{B}=1$, with a minimum amount $\left(\mathrm{LS}_{\mathrm{p}}^{\mathrm{r}}\right.$ ) of manufactured products. Equations number 6 represent the upper bound of the additional capacity and expressions number 7 are non-negativity contraints for all the variables. 


\section{Planning model}

$$
\begin{aligned}
& \min _{\mathrm{f}}=\mathrm{w}_{1}\left(\sum _ { \mathrm { t } } \left(\sum_{\mathrm{r}^{\prime}} \sum_{\mathrm{r}} \sum_{\mathrm{p}}\left(\mathrm{q}_{\mathrm{p}, \mathrm{t}}^{\mathrm{r}, \mathrm{r}^{\prime}} \cdot \mathrm{CA}_{\mathrm{p}}^{\mathrm{r}}\right)+\sum_{\mathrm{r}}\left(\sum_{\mathrm{p}^{\prime}} \mathrm{i}_{\mathrm{p}^{\prime}, \mathrm{t}}^{\mathrm{r}} \cdot \mathrm{CS}_{\mathrm{p}^{\prime}}^{\mathrm{r}}+\sum_{\mathrm{p}}\left(\mathrm{f}_{\mathrm{p}, \mathrm{t}}^{\mathrm{r}} \cdot \mathrm{CP}_{\mathrm{p}}^{\mathrm{r}}+\mathrm{b}_{\mathrm{p}, \mathrm{t}}^{\mathrm{r}} \cdot \mathrm{CB}_{\mathrm{p}}^{\mathrm{r}}+\mathrm{x}_{\mathrm{p}}^{\mathrm{r}} \cdot \mathrm{CR}_{\mathrm{p}}^{\mathrm{r}}\right)\right)\right.\right. \\
& \left.+\sum_{\mathrm{r}} \sum_{\mathrm{p}} \mathrm{Ac}_{\mathrm{t}}^{\mathrm{r}} \cdot \mathrm{y}_{\mathrm{t}}^{\mathrm{r}}\right)+\mathrm{w}_{2} \sum_{\mathrm{p}} \sum_{\mathrm{t}} \sum_{\mathrm{p}} \sum_{\mathrm{p}^{\prime}} \mathrm{b}_{\mathrm{p}, \mathrm{t}}^{\mathrm{r}, \mathrm{r}^{\prime}} \\
& \left(\mathrm{i}_{\mathrm{p}, \mathrm{t}}^{\mathrm{r}}=\mathrm{i}_{\mathrm{p}, \mathrm{t}-1}^{\mathrm{r}}+\mathrm{f}_{\mathrm{p}, \mathrm{t}-\mathrm{DP}}^{\mathrm{r}}-\sum_{\mathrm{r}^{\prime}}^{\mathrm{r}} \mathrm{r}_{\mathrm{p}, \mathrm{t}}^{\mathrm{r} \mathrm{r}^{\prime}} \quad ; \quad \mathrm{i}_{\mathrm{p}, \mathrm{t}}^{\mathrm{r}}=\mathrm{i}_{\mathrm{p}, \mathrm{t}-1}^{\mathrm{r}}+\sum_{\mathrm{r}^{\prime}} \mathrm{q}_{\mathrm{p}, \mathrm{t}}^{\mathrm{r}^{\prime}, \mathrm{r}}-\sum_{\mathrm{p}^{\prime}}\left(\mathrm{K}_{\mathrm{p}, \mathrm{p}^{\mathrm{p}}}^{\mathrm{r}} * \mathrm{f}_{\mathrm{p}^{\prime}, \mathrm{t}}^{\mathrm{r}}\right) \quad \forall \mathrm{p}, \mathrm{t}, \mathrm{r}\right. \\
& \mathrm{b}_{\mathrm{p}, \mathrm{t}}^{\mathrm{r}, \mathrm{r}^{\prime}}=\mathrm{b}_{\mathrm{p}, \mathrm{t}-1}^{\mathrm{r}, \mathrm{r}^{\prime}}+\mathrm{d}_{\mathrm{p}, \mathrm{t}}^{\mathrm{r}^{\prime}, \mathrm{r}}-\mathrm{l}_{\mathrm{p}, \mathrm{t}}^{\mathrm{r}, \mathrm{r}^{\prime}}-\mathrm{x}_{\mathrm{p}, \mathrm{t}}^{\mathrm{r}, \mathrm{r}^{\prime}} \quad \forall \mathrm{p}, \mathrm{t}, \mathrm{r}, \mathrm{r}^{\prime} \\
& \left\{\sum_{\mathrm{p}}\left(\alpha_{\mathrm{p}} \cdot \sum_{\tau=1}^{\mathrm{DP}} \mathrm{f}_{\mathrm{p}, \mathrm{r}}^{\mathrm{r}} \mathrm{r} \tau+1\right) \leq \mathrm{CapR}_{\mathrm{t}}^{\mathrm{r}}+\mathrm{y}_{\mathrm{t}}^{\mathrm{r}} ; \sum_{\mathrm{p} \in \mathrm{P}^{\mathrm{r}}} \delta_{\mathrm{p}} \cdot \mathrm{i}_{\mathrm{p}, \mathrm{t}}^{\mathrm{r}} \leq \mathrm{CapS}^{\mathrm{r}} ; \sum_{\mathrm{p} \in \widehat{\mathrm{P}}^{\mathrm{r}}} \beta_{\mathrm{p}} \cdot \mathrm{l}_{\mathrm{p}}^{\mathrm{r}, \mathrm{r}^{\prime}} \leq \mathrm{CapT}^{\mathrm{r}, \mathrm{r}^{\prime}} \quad \forall \mathrm{r}, \mathrm{r}^{\prime}\right. \\
& \mathrm{f}_{\mathrm{p}, \mathrm{t}}^{\mathrm{r}} \geq \mathrm{B} * \mathrm{LS}_{\mathrm{p}}^{\mathrm{r}} \quad \forall \mathrm{p}, \mathrm{t}, \mathrm{r}
\end{aligned}
$$

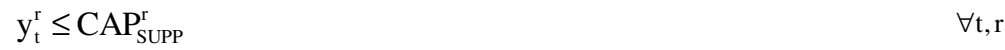

$$
\begin{aligned}
& \mathrm{q}_{\mathrm{p}, \mathrm{t}}^{\mathrm{r}, \mathrm{r}^{\prime}}, \mathrm{i}_{\mathrm{p}, \mathrm{t}}^{\mathrm{r}}, \mathrm{b}_{\mathrm{p}, \mathrm{t}}^{\mathrm{r}, \mathrm{r}^{\prime}}, \mathrm{l}_{\mathrm{p}, \mathrm{t}}^{\mathrm{r}, \mathrm{r}^{\prime}}, \mathrm{d}_{\mathrm{p}, \mathrm{t}}^{\mathrm{r}, \mathrm{r}^{\prime}} \geq 0 \quad \forall \mathrm{p}, \mathrm{t}, \mathrm{r}, \mathrm{r}^{\prime}
\end{aligned}
$$

\begin{tabular}{|c|c|c|c|c|c|}
\hline \multicolumn{4}{|c|}{ PARAMETERS } & \multicolumn{2}{|c|}{ INDEXES } \\
\hline $\mathrm{H}$ & Planning horizon & $\mathrm{CapS}_{\mathrm{t}}^{\mathrm{r}}$ & Storage capacity & $\mathrm{r}, \mathrm{r}^{\prime}$ & Index of PU \\
\hline $\mathrm{K}_{\mathrm{p}, \mathrm{p}^{\prime}}^{\mathrm{r}}$ & Bill of materials coefficients & $\operatorname{CapT}_{t}^{r, r^{\prime}}$ & Transport capacity & $\mathrm{p}, \mathrm{p}^{\prime}$ & Index of products \\
\hline $\mathrm{DP}_{\mathrm{p}}^{\mathrm{r}}$ & Production delay & $\mathrm{PV}_{\mathrm{p}}^{\mathrm{r}}$ & Unitary purchase mean cost & $\mathrm{t}$ & Index of planning period \\
\hline $\mathrm{DL}^{\mathrm{r}, \mathrm{r}^{\prime}}$ & Transport delay & $\mathrm{CA}_{\mathrm{p}}^{\mathrm{r}}$ & Unitary sale price & & \\
\hline$\alpha_{\mathrm{p}}$ & Quantity of resource required & $\mathrm{CS}_{\mathrm{p}}^{\mathrm{r}}$ & Unitary inventory mean cost & $\mathrm{w}_{1}, \mathrm{w}_{2}$ & Criteria weights \\
\hline$\beta_{\mathrm{p}}$ & Unitary weight or volume & $\mathrm{CP}_{\mathrm{p}}^{\mathrm{r}}$ & Unitary production mean cost & $L S_{p}^{r}$ & Product $\mathrm{p}$ lot-size in $\mathrm{PU}_{\mathrm{r}}$ \\
\hline$\delta_{\mathrm{p}}$ & Space for stocking a unit $\mathrm{p}$ & $\mathrm{CB}_{\mathrm{p}}^{\mathrm{r}}$ & Unitary backorder cost & & \\
\hline $\operatorname{CapR}_{\mathrm{t}}^{\mathrm{r}}$ & Production capacity & $\mathrm{CR}_{\mathrm{p}}^{\mathrm{r}}$ & Unitary shortage cost & & \\
\hline \multicolumn{6}{|c|}{ VARIABLES } \\
\hline $\mathrm{i}_{\mathrm{p}, \mathrm{t}}^{\mathrm{r}}$ & \multicolumn{5}{|c|}{ Inventory level of product $\mathrm{p}$ in the $\mathrm{PU}_{\mathrm{r}}$ at the end of period $\mathrm{t}$} \\
\hline$b_{p, t}^{r, r}$ & \multicolumn{5}{|c|}{ Amount of products $\mathrm{p}$ in the $\mathrm{PU}_{\mathrm{r}}$ delivered in late for its customer $\mathrm{r}^{\prime}$ at the end of period $\mathrm{t}$} \\
\hline $\mathrm{b}_{\mathrm{p}, \mathrm{t}}^{\mathrm{r}}$ & \multicolumn{5}{|c|}{ Final customers' backorders of product $\mathrm{p}$ in the $\mathrm{PU}_{\mathrm{r}}$ at the end of period $\mathrm{t}$} \\
\hline$x_{p}^{r}$ & \multicolumn{5}{|c|}{ Amount of products $\mathrm{p}$ never delivered to customer $\mathrm{r}$} \\
\hline $\mathrm{f}_{\mathrm{p}, \mathrm{t}}^{\mathrm{r}}$ & \multicolumn{5}{|c|}{ Production quantity of product $\mathrm{p}$ to launch in the $\mathrm{PU}_{\mathrm{r}}$ during period $\mathrm{t}$} \\
\hline$d_{\mathrm{p}, \mathrm{t}}^{\mathrm{r}, \mathrm{r}^{\prime}}$ & \multicolumn{5}{|c|}{ Demand of product $\mathrm{p}$ during period $\mathrm{t}$ from $\mathrm{PU}_{\mathrm{r}}$ to $\mathrm{PU}_{\mathrm{r}}$} \\
\hline $1_{\mathrm{p}, \mathrm{t}}^{\mathrm{r}, \mathrm{r}^{\prime}}$ & \multicolumn{5}{|c|}{ Delivery quantity of product $\mathrm{p}$ launching during period $\mathrm{t}$ from $\mathrm{PU}_{\mathrm{r}}$ to $\mathrm{PU}_{\mathrm{r}}$} \\
\hline $\mathrm{q}_{\mathrm{p}, \mathrm{t}}^{\mathrm{r}^{\prime}, \mathrm{r}}$ & \multicolumn{5}{|c|}{ Quantity of component $p$ received during period $t$ at the $P U_{r}$ from $P U_{r^{\prime}}$} \\
\hline
\end{tabular}

\section{Notations}

The criterion $\left(\mathrm{C}_{\mathrm{f}}\right)$ includes financial and non financial aspects of the performance of the supply chain, mainly ensuring efficiency through the minimization of costs and good service quality (effectiveness) if backorders are reduced. The responsiveness of the supply chain is studied according to the variation of the planning period value. 


\section{Experimental Setup and Results}

A supply chain (SC) instance is defined to assess the sensitivity of the performance of the SC in response to the variation of different parameters. The instance studied in this paper is a multi-stage supply chain structure that produces tables and shelves. Figure 2 shows the key parameters that can enable to understand the discussion of the experimental results. Readers interested in a detailed description of the case study are referred to François et al. (2005).

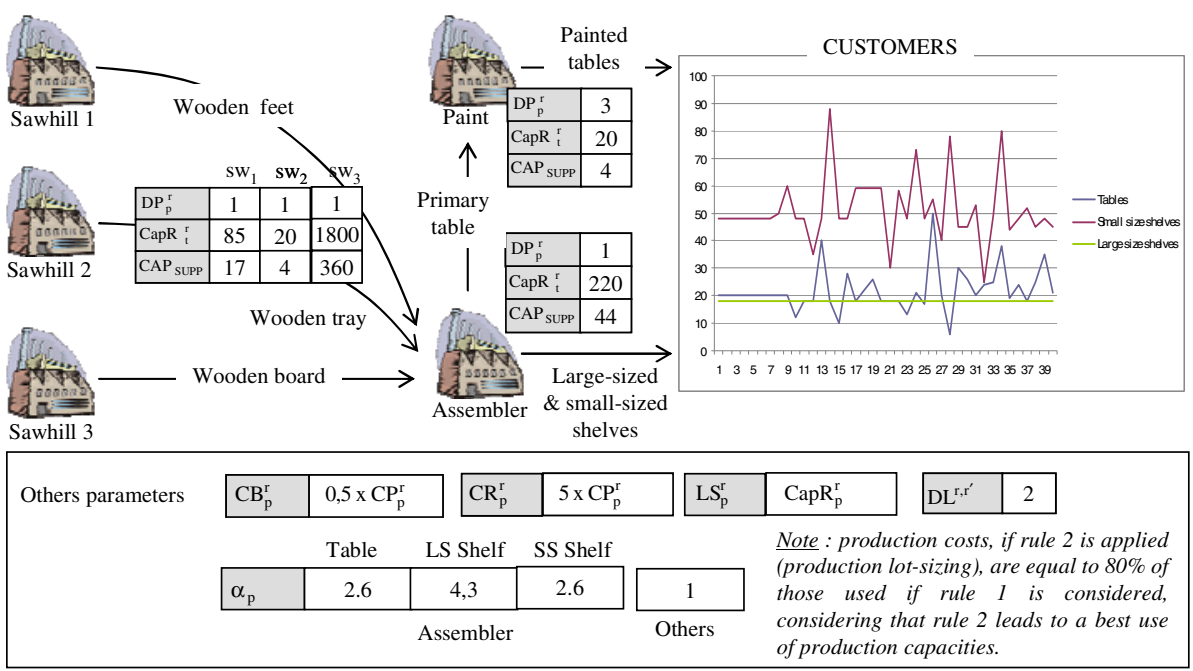

Fig. 2. The studied SC instance

We consider this paper to be a preliminary work that will prepare the ground for a more extensive research in the future. Therefore, of the ten determining factors identified in section 2 (see Table 1), we have tested the impact of only two of them on SC performance. The two factors tested are lot sizing and frozen time fence. For lot sizing, we looked at two strategies: Lot-For-Lot (LFL) and Fixed-Period-Quantity (FPQ); and for frozen time fence, we also looked at two cases: a small fence of 5 periods and a large fence of 10 periods. The impact of these determinants is analyzed with respect to the three dimensions (efficiency, effectiveness and responsiveness) of $\mathrm{SC}$ performance, as presented in section 2. Here, we note that efficiency is measured in terms of the total cost of the production plan, effectiveness in terms of shortages (quantities not delivered at all) and responsiveness in terms of delayed deliveries (quantities delivered but not on time). Table 2 shows the main results obtained from a total of fifteen scenarios that we studied. The first scenario considers the use of the normal capacity while the other fourteen take into consideration the additional capacity. 
Table 2. Results of the experiments

\begin{tabular}{|c|c|c|c|c|c|c|c|}
\hline $\begin{array}{l}\text { Scenario } \\
\text { Number }\end{array}$ & $\begin{array}{c}\text { Over- } \\
\text { capacity }^{1}\end{array}$ & Lot Sizing & $\begin{array}{c}\text { Frozen } \\
\text { Time } \\
\text { Fence }\end{array}$ & Criteria $^{2}$ & Total Cost & $\begin{array}{l}\text { Quantity } \\
\text { delayed }\end{array}$ & Shortages \\
\hline 1 & $\mathrm{~N}$ & Lot-For-Lot & 5 & $\mathrm{C}$ & $1026492 €$ & 3650 & 743 \\
\hline 2 & $\mathrm{Y}$ & Lot-For-Lot & 5 & $\mathrm{C}$ & $835858 €$ & 1441 & 229 \\
\hline 3 & $\mathrm{Y}$ & Lot-For-Lot & 5 & $\mathrm{D}$ & $866713 €$ & 1065 & 191 \\
\hline 4 & $\mathrm{Y}$ & Lot-For-Lot & 5 & $\mathrm{C}+\mathrm{D}$ & $840810 €$ & 1094 & 195 \\
\hline 6 & $\mathrm{Y}$ & Lot-For-Lot & 10 & $\mathrm{C}$ & $831422 €$ & 1331 & 200 \\
\hline 7 & $\mathrm{Y}$ & Lot-For-Lot & 10 & $\mathrm{D}$ & $859650 €$ & 889 & 168 \\
\hline 8 & $\mathrm{Y}$ & Lot-For-Lot & 10 & $\mathrm{C}+\mathrm{D}$ & $835190 €$ & 967 & 179 \\
\hline 10 & Y & $\begin{array}{c}\text { Fixed-Period- } \\
\text { Quantity }\end{array}$ & 5 & $\mathrm{C}$ & $821735 €$ & 1376 & 218 \\
\hline 11 & Y & $\begin{array}{l}\text { Fixed-Period- } \\
\text { Quantity }\end{array}$ & 5 & D & $855839 €$ & 1275 & 233 \\
\hline 12 & $\mathrm{Y}$ & $\begin{array}{c}\text { Fixed-Period- } \\
\text { Quantity }\end{array}$ & 5 & $\mathrm{C}+\mathrm{D}$ & $828125 €$ & 1329 & 236 \\
\hline 13 & Y & $\begin{array}{l}\text { Fixed-Period- } \\
\text { Quantity }\end{array}$ & 10 & $\mathrm{C}$ & $875353 €$ & 1732 & 323 \\
\hline 14 & Y & $\begin{array}{l}\text { Fixed-Period- } \\
\text { Quantity }\end{array}$ & 10 & D & $913123 €$ & 1641 & 339 \\
\hline 15 & Y & $\begin{array}{l}\text { Fixed-Period- } \\
\text { Quantity }\end{array}$ & 10 & $\mathrm{C}+\mathrm{D}$ & $887358 €$ & 1678 & 352 \\
\hline
\end{tabular}

\section{Discussion and Conclusion}

For each combination of lot sizing and frozen time fence, three simulations are performed: cost minimization (C), delay minimization (D) and cost and delay minimization $(\mathrm{C}+\mathrm{D})$. We can see clearly from Table 2 that the most economic scenarios are those where simulation is done with respect to cost. We notice that when simulation is done with respect to delay, total cost deteriorates where as the quality of service improves (less shortages and late deliveries). If this sounds normal, an intriguing observation lies rather in the various combinations of lot sizing and frozen time fence. These first exploratory results seem to imply that when lot-for-lot (LFT) is used, a large frozen time fence is a better strategy since all three performance criteria (efficiency, effectiveness and responsiveness) are better than in the case of a small frozen time fence. On the contrary, when a fixed-period-quantity (FPQ) is used, it is better to go for a small frozen time fence. We think that a LFL strategy tries to quickly adapt production to variations in demand, even when these variations are forecasts. Consequently, in order to avoid a bullwhip effect and have a better supply chain performance, it is important to balance this responsiveness capability with a minimum of stability within the inputs. On the other hand, the FPQ strategy tries to optimize 
production capabilities irrespective of demand variations. It then seems to be more important for a planning manager to track and capture demand variations very frequently in order to be able to use his additional capacity as and when necessary.

In conclusion, as a determining factor, a lot-for-lot strategy can be said to be related more to effectiveness and responsiveness while a large frozen time fence is more inclined towards efficiency. On the other hand, a fixed-period-quantity strategy is related more to efficiency while a small frozen time fence inclines more towards effectiveness and responsiveness. As we have already mentioned, this is an exploratory work; in our further research, we will not only study more determining factors, but will also increase the performance spectrum to include agility and leagility as developed in our framework in section 2.

\section{References}

1. Chase, R.B., Jacobs, F.R., Aquilano, N.J.: Operations management for competitive advantage. McGraw-Hill, New York (2004)

2. De Man, R., Burns, T.R.: Sustainability: supply chains, partner linkages, and new forms of self-regulation. Human Systems Management 25, 1-12 (2006)

3. Francois, J., Deschamps, J.C., Fontan, G., Bourrieres, J.P.: Assessing the impact of control architectures on Supply Chains performances. In: 4th International Workshop on Performance Measurement, Bordeaux, France (2005)

4. François, J., Deschamps, J.-C., Fontan, G., Bourrieres, J.P.: Collaborative planning for enterprises involved in different supply chains. In: IEEE SSSM 2006, International Conference on Service Systems and Service Management, Troyes, France (2006)

5. Naylor, J.B., Naim, M.M., Berry, D.: Leagility: interfacing the lean and agile manufacturing paradigm in the total supply chain. International Journal of Production Economics 62, 107-118 (1999)

6. Olhager, J., Selldin, E.: Manufacturing planning and control approaches: market alignment and performance. International Journal of Production Research 45(6), 1469-1484 (2007)

7. Rainbird, M.: Demand and supply chains: the value catalyst. International Journal of Physical Distribution and Logistics Management 34(3/4), 230-250 (2004)

8. Reiner, G., Hofmann, P.: Efficiency analysis of supply chain processes. International Journal of Production Research 44(23), 5065-5087 (2006)

9. Slack, N., Chambers, S., Johnston, R.: Operations management. Prentice Hall, London (2007)

10. Stevenson, W.J.: Operations management. McGraw-Hill, New York (2005)

11. Wacker, J.G., Sheu, C.: Effectiveness of manufacturing planning and control systems on manufacturing competitiveness: evidence from global manufacturing data. International Journal of Production Research 44(5), 1015-1036 (2006)

12. Walters, D.: Effectiveness and efficiency: the role of supply chains management. The International Journal of Logistics Management 17(1), 75-94 (2006)

13. Zokaei, K., Hines, P.: Achieving consumer focus in supply chains. International Journal of Physical Distribution and Logistics Management 37(3), 223-247 (2007) 